\title{
LARGE APERTURE OPTICAL SWITCHING DEVICES
}

\author{
J. Goldhar \\ and
}

M. A. Henesian

\section{This paper was prepared for submittal to SPIE Meeting \\ Los Angeles, CA January 22-27, 1984}

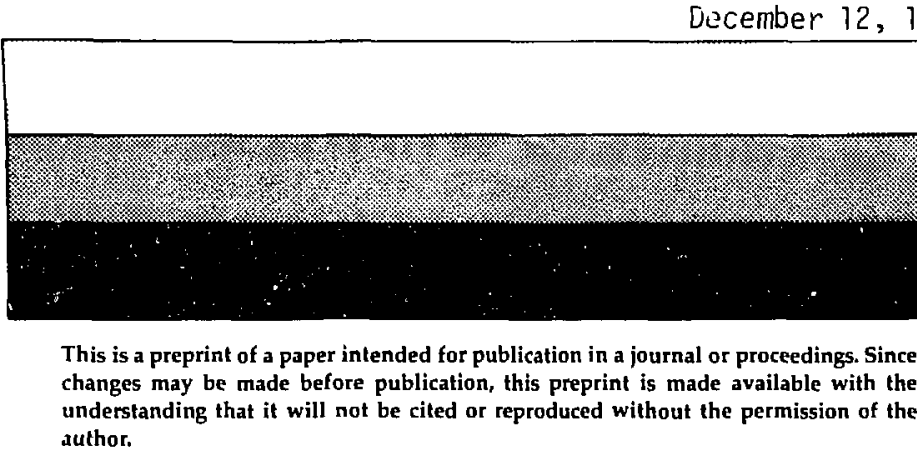

\section{DISCLAIMER}

This report was prepared as an account of work sponsored by an agency of the United States Government. Neither the United States Government nor any agency thereof, nor any of their employees, makes any warranty, express or implied, or assumes any legal liability or responsibility for the accuracy, completeness, or usefulness of any information, apparatus, product, or process disclosed, or represents that its use would not infringe privately owned rights. Reference herein to any specific commercial product, process, or service by trade name, trademark, manufacturer, or otherwise does not necessarily constitute or imply its endorsement, recommendation, or favoring by the United States Government or any agency thereof. The views and opinions of auihors expressed herein do not necessarily state or reflect those of the United States Governtuent or any agency thereof.

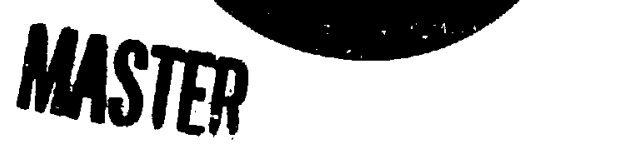

$$
\text { Prte }
$$

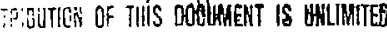


Large aperture optical switching devices

\author{
J. Goldhar and M. A. H.?nesian* \\ Lawrence Livermore National Laboratory \\ University of California \\ P.0. Box 5508, L-490 \\ Livermore, California 94550
}

\begin{abstract}
We have developed a new approach to constructing large aperture optical switches for next generation inertial confinement fusion lasers. A transparent plasma electrode formed in low pressure ionized gas acts as a conductive coating to allow the uniform charging of the optical faces of an electro-optic material. In this manner large electric fields can oe applied longitudinally to large aperture, high aspect ratio Pockels cells. We propose a four-electrode geometry to create the necessary nigh conductivity plasma sheets, and have demonstrated fast (< $10 \mathrm{nsec}$ ) switching in a $5 \times 5 \mathrm{~cm}$ aperture $K 0^{\star} \mathrm{P}$ Pockels cell with such a design. Detailed modelling of Pockels cell performance with piasma electrodes has been carried out for 15 and $30 \mathrm{~cm}$ aperture designs.
\end{abstract}

*Work performed under the auspices of the U.S. Department of Energy by Lawrence Livermore National Laboratory under Contract No. W-7405-ENG-48. 
Introduction

System architectures for very large inertial confinement fusion lasers require active optical elements with apertures on the order of one meter. ' Large aperture optical switches are needed for isolation of stages, switch-out from regenerative amplifier cavities and protection from target retroreflections. No conventional optical switch technology is scalaole to such large apertures. Pockels cells with ring electrodes ${ }^{2}$ require crystal tnickness comparable to the aperture. Thin crystal Pockels cell designs using transparent conducting metallic films ${ }^{3}$ or liquid layers ${ }^{4}$ have also been proposed, but have unacceptable resistivity at large apertures or are not appropriate for use with high intensity laser beams. Other approaches include fas? Faraday rotators 5 or transient volumetric thermal gratings, ${ }^{6}$ but still require major technical developments before their feasibility can be evaluated. We are pursuing a promising new approach to large aperture electrooptical switching which utilizes transparent plasma electrodes. ${ }^{7}$ A thin electro-optical material is exposed to a glow discharge plasma on each face. The plasma acts as a transparent cunductive coating allowing uniform charging of each surface to the required potential. Thus, high aspect ratio electro-optic cells can be constructed.

These might include Pockels cells using linear electro-optic effects in crystals, electro-optically tuned second harmonic generation cells, and quasi-transverse Kerr cells with quadratic electro-optic liquids and glasses. We have demonstrated the plasma electrode concept with a $5 \times 5 \times 1$ CIn KDÆP Pockels cell and are studying plasma characteristics at this 
aperture and in a $20 \times 20 \mathrm{~cm}$ discharge chamber. We have also demonstrated an electro-optically tuned second harmonic switch using Type I KDP in the longitudinal Pockels' configuration. ${ }^{8}$ Presented Delow are recent results for a $5 \times 5 \mathrm{~cm}$ Pockels cell with plasma electrodes and considerations for scaling to larger apertures.

The Four Electrode Geometry for Plasma Electrode Cells

The most promising geometry for Pockels type cells with plasina electrodes is illustrated in Fig. 1. A pair of electrodes on each side of the crystal is used to establish the initial sheets of glow discharge in low pressure gas covering the entire optical aperture. Since the current flows parallel to the crystal, no electric field is applied along the optical axis and the pre-ionization current does not affect the polarization of the transmitted notical beam. One piir of electrodes can then be used at a later time, once the desired plasma conditions are established, to charge up the crystal to the required voltage. This four electrode design allows one to establish the initial plasma conditions independently of the voltage pulse requirements for electro-optic switching.

Unlike the metallic film or liquid conductors, a plasma is a very nonlinear medium and there are regimes of operation which are highly undesirable. For example, with insufficient pre-ionization, a large jitter in switching time is observed, and copious amounts of r.f. radiation are generated by the cell. At moderate pre-ionization levels plasma resistance is a function of switching voltage and very slow 
optical rise times are observed for low voltages. However, proper choice of operating parameters with this geometry allows one to obtain rise times in the nanosecond regime and with no observable jitter.

\section{Pockels Cell Experiments}

A Pockels cell of the design illustrated in Fig. I was constructed and tested. A $K U \star P$ crystal $1 \mathrm{~cm}$ thick and with an aperture of $5 \times 5 \mathrm{~cm}^{2}$ was potted into a plexiglass holder with a two-part silicone elastometer. The chamber body was constructed from lucite. The two sections were evaluated and filled with gas through separate long coiled polyethylene fill lines in order to electrically isolate the two sides. Typical fill pressure was 10 Torr of helium. In order to obtain reproducible electrical performance this system required frequent ( 2 every $1 / 2 \mathrm{hr}$ ) evacuation and refill. The most likely reason for this was the outgassing of the lucite parts and the fill lines.

Helium gas was chosen for these experiments for two reasons. The ultimate lifetime of the cell will be determined by the destruction of optical surfaces by sputtering due to ion bombardment, which suggests that a lighter ion will lead to significancly longer lifetimes. Also, a low breakdown voltage and low plasma resistance are also desirable. We saw no damage to the crystal in more than $10^{4}$ shots at $1 H_{\bar{\alpha}}$. Gas contamination in our cell had a significant effect on the discharge characteristics and the plasma resistance we observed was higher than expected for pure helium. 
The electrical circuit used to pulse the cell is shown in Fig. 2 . Two separate thyratron switched pulsers were used, one to provide the pre-ionization voltage, and the other, the electro-optic switching pulse. The switching pulse was derived from a pulse charged cable and a self-triggered low inductance spark-gap. A spark-gap spacing of $2.5 \mathrm{~mm}$ with rounded tungsten electrodes, with $\approx 40$ psi of compressed air gave good pulse-steepening performance. Voltage pulses of $21 \mathrm{nsec}$ rise time and 25 nsec duration at $\imath 20 \mathrm{kV}$ were delivered to the fockels cell via a 100 nsec delay line. The cell was operated as a high impedance load, and thus a voltage doubling of the charged cable voltage occurred at the cell. Somewhat faster turn on times could have been obtained if a high voltage pulser of twice the voltage was used and the cell was shunted with a $50 \Omega$ load. The pre-ionization current was adjusted by varying cine pre-ionization voltage from 2.5 to $17 \mathrm{kV}$ and by changing the Dallast resistors.

To use the plasma electrode Pockels cell depicted in Fig. 1 as an optical switch, it must be placed between a "polarizer" and an "analyzer", which are aligned orthogonal to one another and oriented along the $x$ and $y$ crystallographic axes. The light propagates along the $z$ or optical axis, normal to the crystal face, which is also the direction of the applied electric field. 'In this longitudinal electro-optic configuration, with zero potential difference between the crystal faces, no light is transmitted through the switch. For an instantaneous voltage $V(t)$ across the crystal, the optical transmission through the "analyzer" is given by 


$$
T(t)=\frac{S(t)}{S_{n}}=\sin ^{2} \quad\left(\frac{\pi}{2} \frac{V(t)}{V}\right)
$$

where $V_{\pi}$ is the voltage for a half-wave phase retardation between waves polarized along the "fast" and "slow" electro-optic axes. For uniaxial crystals of tetragonal point group symmetry, including crystals of the KDP isomorphous family,

$$
V_{\pi}=\frac{\lambda}{2 n_{0}^{3} r_{63}}
$$

where $r_{63}$ is the relevant coefficient of the electro-optic tensor. At a wavelength of $1.054 \mu m$, for $K D P$ the half-wave voltage is $V_{\pi}=19.3$ $K V$, and for $90 \%$ deuterated $K D \star P, V_{\pi}=7.4 \mathrm{kV}$ for the "clamped" or nigh frequency (> $1 \mathrm{MHz}$ ) electro-optic effect. ${ }^{10}$

To minimize Fresnel reflection losses at the crystal faces (not accounted for in Eqn. 1) and to increase the optical rise-time performance (to be discussed later), Pockels cells with anti-reflection coated glass plates and index-matching fluid at each crystal to glass interface car. be constructed as depicted in Fig. 3. For such a "sandwich" construction, the actual voltage $v_{k}$ across the crystal in terms of external voltage $V_{0}$ is reduced as in a capacitive voltage divider:

$$
v_{k}=\frac{C_{\text {total }}}{C_{\text {crystal }}} \cdot V_{0}
$$

When the index-matching fluid layers are thin, the capacitive impedance of the fluid can be neglected and Eqn. 3 becomes

$$
v_{k}=v_{0} /\left[1+\frac{2 t}{d} \frac{\varepsilon_{k}}{\varepsilon_{w}}\right]
$$


where $E_{k}$ is the high frequency dielectric constant of the crystal of thickness $d$, and $\varepsilon_{w}$ is the dielectric constant of the windows, each of equal thickness $t$. When $V(t)$ in Eqn. $I$ is taken as the external applied voltage, the nalf-wave voltage for the cell, denoted $V_{0 \pi}$, must be calculated from Eqn. 4 with $v_{k}=v_{\pi}$ taken from Eqn. 2. The nigh frequency dielectric constant along the optical axis for KDP is $\varepsilon_{z}=20$ and for $90 \%$ deuterated $K D * P$ is $\varepsilon_{z}=45$. For fused silica windows, $\varepsilon_{w}$ can range from 3.75 to 4.0 . For several large aperture electro-optic switch geometries that we shall consider later, the nalf-wave voltage for the KDP or $K D \star P-g l a s s$ plate sandwich construction will be a factor of 4 to 16 times the bare crystal value.

In our initial experiments a bare $K D^{\star P}$ crystal was used. The electro-optic effect was observed by probing the cell with a $1 \mathrm{~mW}$ beam from a HeNe laser. Crossed polarizers were placed before and after the cell and a fast photomultiplier was used as a detector. The detection system response time was estimated to be about $20 \mathrm{nsec}$. The observed half-wave voltage at $633 \mathrm{~nm}$ based on peak transmission through the polarizers was $\imath 5 \mathrm{kV}$, in reasonable agreement with a predicted $4.4 \mathrm{kV}$ for a "clamped" (i.e. nigh frequency) electro-optic effect in $90 \%$ deuterated $K D \star P$.

In these preliminary experiments, the circuit used to pulse the cell was similar to that shown in Fig. 2, without the use of the charged cable and self-triggered spark-gap. The pre-ionization voltage was typically set at $10 \mathrm{kV}$ with $5 \mathrm{k} \Omega$ ballast resistors. The combination of high plasma resistance ( $1 \sim 1.5 \mathrm{k} \Omega$ estimate) at the low electro-optic 
voltage, and the high capacitance of the bare crystal ( $\sim 100 \mathrm{pf}$ ), unfortunately resulted in slow optical turn-on times. The plasma electrode-K$D^{\star} P$ crystal combination appeared to be acting as a resistive transmission line. By probing different points of the crystal with the laser we could see a voltage propagation time of $\sim 50$ nsec across the 5 $\mathrm{cm}$ aperture, and optical rise-times of $\imath 100 \mathrm{nsec}$.

The Pockels cell performance was significantly improved when a fused silica plate, $2.5 \mathrm{~mm}$ thick was placed in series with the KD*P crystal, and the pre-ionization level increased above that used with the bare crystal. The plate was glued to one crystal face with the transparent silicone elastometer to provide some index-matching and mechanical stability. The low dielectric constant of the fused silica ( $\varepsilon \sim 3.75$ ) relative to the bare $K D^{\star P}\left(\varepsilon_{z} \imath 45\right)$ resulted in most of the voltage drop occurring across the fused silica plate. This raised the effective half-wave voltage of the cell by a factor of 4.0 over the bare crystal value. The capacitance of the KD*P-fused silica sandwich dropped similarly by a factor of 4.0 to $\approx 25 \mathrm{pf}$.

In these later experiments, the electro-optic effect was probed at nigh temporal resolution by using a single-frequency beam from an argon-ion laser at $514.5 \mathrm{~nm}$, with a nominal output of 1 watt. An S-20 biplanar vacuum photodiode was used as a detector and the detection system response time was estimated to be better than $1 \mathrm{nsec}$. Figs. 4 and 5 show typical results obtained with the argon-ion laser and the spark-gap steepened pulser circuit. 
The oscilloscope trace shown in Fig. 4 is a representative voltage pulse sent to the Pockels cell of nominally $20 \mathrm{kV}$. This trace was obtained by picking off the voltage near the beginning of the $100 \mathrm{nsec}$ delay line with a $5 \mathrm{k} \Omega$ resistive probe. To verify the pulse shape inside the Pockels cell, the crystal was removed and a $5 \mathrm{k} \Omega$ resistive prode connected acrrss the electrodes. No significant distortion of the pulse shape was observed. Fig. 5 is an oscilloscope trace of a typical switcned-out optical pulse, indicating better than 10 nsec rise-time performance for our $5 \mathrm{~cm}$ aperture Pockels cell. The performance of our Pockels cell was limited primarily by plasma resistance, feed-through inductance and the stray capacitance ( $\sim 25 \mathrm{pf}$ ) of the plexiglass crystal holder. An advanced cell design which minimizes stray capacitance, and which has low inductance feed-throughs at the electrodes would be expected to have an optical rise-time of $3-4 \mathrm{nsec}$ at the $5 \times 5$ cm size when pulsed by a $50 \Omega$ driver.

A variation of the pre-ionization current was observed to change the initial plasma resistance and thus effect the voltage and optical risetimes. Fig. 6 shows a plot of the observed optical risetime (from 10 to $90 \%$ ) for the $5 \times 5$ Pockels cell vs. pre-ionization current and indicates the improved risetime performance with increased pre-ionization. A model for this dependence and scaling with aperture will be discussed in a following section.

To observe discharge behavior and measure plasma resistance on a larger scale we constructed a $20 \times 20 \mathrm{~cm}$ aperture cell of the same four-electrode design, with a $\mathrm{I} \mathrm{cm}$ thick lucite plate replacing the $K D^{\star} \mathrm{P}$ 
crystal. The cell was driven with a $50 \Omega$ line at $75 \mathrm{kV}$ and the propagation of the voltage pulse across the cell was measured with fast nigh voltage prodes. Even at the lowest pre-ionization levels the propagation time across the cell was less than $20 \mathrm{~ns}$. A $2 \mathrm{~cm}$ thick KD*P crystal in a sandwich design with two $5 \mathrm{~mm}$ thick fused silica plates has approximately the same capacitance as the $1 \mathrm{~cm}$ thick lucite plate, and would reach full charge in about the same time. Thus, we have good reason to believe that such a large aperture Pockels cell of the four-electrode design will have good optical performance.

\section{Modelling Plasma Electrode Parameters and Optical Perfcrmance}

The Pockels cell with plasma electrodes can be modeled as a resistive transmission line with a nonlinear, time dependent plasma resistance. In our design the voltage is applied from one side only. The propagation of a voltage pulse across the cell is thus governed by the diffusion equation:

$$
\frac{\partial V}{\partial t}=\frac{1}{R C} \frac{\partial^{2} V}{\partial x^{2}}
$$

with appropriate boundary conditions, where $R$ and $C$ are the resistance and capacitance per unit length along the pulse propagation direction $x$.

For short pulses the plasma resistance per plasma sheet can be approximately expressed as

$$
\frac{1}{R}=\frac{1}{R_{0}}+\int_{0}^{t} \frac{I\left(t^{\prime}\right) d t^{\prime}}{A}
$$


where $R_{0}$ is the initial resistance determined by the level of pre-ionization, $I(t)$ is the instantaneous current density and $A$ is a coefficient accounting for electron avalanching. In principle, the coefficient A can be calculated from the electron mobility and Townsend's first ionization coefficient. However, because of gas impurities and the complex electrode geometry it is best to determine it empirically. The initial plasma resistance was estimated from the voltage-current characteristics of the pre-ionization circuit. Since the pre-ionization pulse was sufficiently long for a steady-state discharge to occur, the resistance $R_{0}$ was only a function of the instantaneous pre-ionization current. A resistance per $\mathrm{cm}$ along the discharge propagation direction of

$$
R_{0}=\frac{300 \Omega}{I(a m p)} \mathrm{cm}^{-1}
$$

at 10 Torr was found to best fit the pre-ionization data. Using the coefficient $A=3.10^{4} \Omega \mathrm{amp}^{-1} \mathrm{sec}^{-1}$ in Eqn. 6 we get reasonable agreement between the experimental data and the optical rise-time calculated from Eqn. 1 and numerical modelling of Eqns. 5 and 6 . The solid line plot in Fig. 6 slows the adel calculation, assuming a $50 \Omega$ oriving line and a cell capacitance of $50 \mathrm{pf}$.

\section{Projected Performance of Large Aperture Pockels Cells}

The plasma electrode concept is ideally suited th the construction of Pockels cells with apertures greater than $5 \mathrm{~cm}$. Plasma "sheet" electrodes generated in the four-electrode design apply a uniform electric field over virtually the entire face of the crystal, and thus allow thin crystals to be used. Conventional ring-electrode Pockels 
cells are commercially available up to $10 \mathrm{~cm}$ in diameter, but require $\approx$ $850 \mathrm{~cm}^{3}$ of single crystal material, have a limited contrast ratio of $\imath 200: 1$, and a nigh single-pass loss of $\imath 7 \%$. For high intensity laser applications, thin crystal plasma electrode Pockels cells will have the advantage of substantially lower (by $\sim 5 x$ ) "8"-integral or beam preak-up parameter compared to conventional designs. Thus, considering the many important performance improvements allowed by the plasma electrode concept at large aperture, we will predict the voltage requirements and optical rise-time performance for several realistic large aperture cells.

Specifically, in Tables 1 and 2 we shall consider KDP and KD*P (90\% deuterated) Pockels cells at square apertures of 5,15 , and $30 \mathrm{~cm}$. Since the optical performance with bare crystal surfaces will be disappointing, we assume that the crystal-glass plate construction illustrated in Fig. 3 will de used. A window aspect ratio of nominally 15:1 is assumed for all cases and should provide sufficient window thickness for mechanical strength and good optical figure. Listed in the tables is the crystal thickness $d$, the thickness $t$ of each window, the externai to internal half-wave voltage ratio $V_{0 \pi} / V_{k \pi}$ computed from Eqn. 4, and the resulting external half-wave voltage $V_{0 \pi^{*}}$

In the limit that the plasma resistance is negligible, the Pockels cell charges up as a simple RC circuit with rise-time to $95 \%$ of full voltage at $t_{.95}=3.0 R C$. Here, $R$ is the impedance of the driver and $C$ is equal to the total cell capacitance $C_{\text {total }}$. From Eqn. 1 it is easily shown that the $95 \%$ rise-time of the optical transmission is 
$t_{.95}=1.94 \mathrm{RC}$. In Tables 1 and 2 we calculate the limiting optical rise-time $1.94 \mathrm{FC}$ and compare with the computed $t_{.95}$ when the plasma resistance is included.

To make a realistic assessinent of the optical performance, the time $t$.95 for the optical transmission to exceed $95 \%$ over the entire crystal face will be calculated. Specifically, we shall determine this at the farthest edge of the crystal from the main high voltage pulser. Fig. 7 is a model computation that shows the effect of plasma resistance at the $30 \times 30 \mathrm{~cm}$ aperture on the differential charging rates between the near and far edges of the crystal. A 4 nsec difference in t.95 times for the opposite edges of the crystal illustrates the importance of choosing $t_{.95}$ at the far edge.

A pre-ionization current of 4 amps per $\mathrm{cm}$ of electrode length, will be assumed in calculating the initial plasma resistance per sheet from Eqn. 7. The high voltage driver for the 5 and $15 \mathrm{~cm}$ aperture cells will De assumed to have $50 \Omega$ impedance, and for the $30 \mathrm{~cm}$ aperture cell a $25 \Omega$ impedance. The cell will be taken as an unterminated, high impedance load.

A comparison of Tables 1 and 2 indicates that the KDP Pockels cells have a slight performance advantage over the $K D * P$ cells at the expense of 25\% higher operating voltage. This is due to a lower capacitance of the KDP cells, and a higher half-wave voltage of the KDP compared to KD*P, which results in stronger electron avalanching during the switching pulse that charges-up the crystal. The factor of 3 to 4 difference between the rise-times calculated from the plasma resistance model and the 1.94 RC 
value illustrates the significance of the plasma resistance. With a less conservative pre-ionization current, the rise-time can be macie to approach the limiting value. This is shown in Fig. 8 which plots predicted optical rise-time to $95 \%$ vs. the pre-ionization current at the $30 \mathrm{~cm}$ aperture for $25 \Omega$ and $50 \Omega$ drivers. For uniform pre-ionization it is probably Dest to work at the lower currents, but this will depend on the specific gas, trace impurities, and the electrode configuration. We should note that the model computations based on Eqn. 5 completely neglect inductive transmission line effects. These become important when the predicted rise-time $t_{.95}$ becomes ccinparable to the transit time of an electromagnetic pulse across the cell aperture. For the crystal-glass sandwich geometries considered here the transit time is approximately 0.1 nsec per cm. The predicted rise-times given in Tables 1 and 2 must be convolved with the transit time to account for inductive effects. An approximate value can be obtained by adding the transit time to the predicted rise-time in a root-mean-squared sense. The correct way to solve this problem is by adding the inductive term to the right-hand side of Eqn. 5. For estimating optical performance at apertures greater than $30 \mathrm{~cm}$ we intend to handle it that way in future work.

A sandwich of KUP or KD*P with fused silica plates is a base-line large aperture design that can yield good optical performance. However, in a nigh intensity laser system one will have to leave a fixed gap Detween the crystal and glass plate surfaces and fill them with an appropriate index matcning fluid. To minimize the stress-induced-optical fistortions in the plates the index-matching fluid must be maintained at the pressure of the gas fill. This significantly complicates the mechanical design of a large aperture plasma-electrode Pockels cell. 
Consequently, what is desirable for this type of switch is a "hard" material with electro-optic coefficient lower than KDP, with lower dielectric constant (the two are usually related) and good materials properties for high intensity laser operation. A search for practical electro-optic materials of this sort which would not require index-matching fluid or the sandwich geometry, which can be thin film anti-reflection coated is now in progress.

\section{Acknowledgements}

We would like to thank Don Masquelier, John Lutz and Robert Pasha for their help with the construction of the experimental apparatus and Treva Mauch for preparing this manuscript. We also thank John Murray, Roger Haas, Dave Eimerl, and Lyn Pleasance for useful discussions and john Emmett and Howard Lowdermilk for encouraging this work. 


\section{References}

1. G. W. Gidos, "Special Report: The Status of Short-Wavelength Laser Fusion", Laser Focus/Electro-Optics Vol. 19, No. 10, pp. 95-98 (1983).

2. L. L. Steinmetz, T. W. Pouliot, and B. C. Johnson, Appl. Opt. 12, 1468-1471 (1973); and M. A. Summers, and B. C. Johnson, "Design and Performance of Large Aperture KD*P Pockels Cells", UCRL Report 79952, Uctober 13, 1977.

3. W. T. Pawlewicz, I. B. Mann, W. H. Lowdermilk, and D. Milam, Appl. Phys. Lett. 34, 196-198 (1979).

4. J. M. Thorne, "Final Report, Transparent Liquid Electrodes", Contract 2360309, University of California, Lawrence Livermore National Laboratory, March 1979; and W. E. Martin, "Large Aperture Pockels Cells", Laser Program Annual Report 1979, Lawrence Livermore National Laboratory, Vol. 1, Section 2, pp. 210-213.

5. L. P. Bradley and W. H. Lowdermilk, "Fast, Large-Aperture Optical Switch", Laser Program Annual Report 1977, Lawrence Livermore National Laboratory, Vol. 1, Section 2, pp 156-161.

6. J. Goldhar, "Beam Deflecting Optical Switch Using Volumetric Thermal Gratings", to be published in Applied Optics, January 1, 1984.

7. J. Goldhar, and M. A. Henesian, "Electro-optical Switches with Plasma Electrodes", UCRL Report 89929, October 14, 1983; submitted to Optics Letters.

8. M. A. Henesian, J. Goldhar, and R. A. Haas, to be published. 
9. A. Yariv, Introduction to Optical Electronics, 2nd Ed. (Holt, Rinehart and Winston, New York, 1976), Chapter 9, pp. 253-257.

10. I. P. Kaminow, "Linear Electrooptic Materials", in Handbook of Laser Science and Technology, Vol. III: Optical Materials Part A, ed. by M. J. Weber (CRC Press, Boca Raton, FL, 1984).

\section{HSC I WVIR}

This document wa prepared as an account of work yponsored by an agens? if

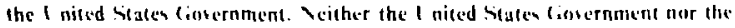

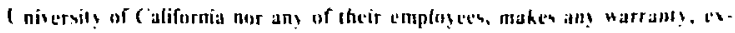
press or implicd, or assumes any lead Jiabilit or respomibility for the accuracy. conpletemess, or uefofulness of any information, apparatus, preduct, or process disclused, ar sepreserts that its use nould not infringe privately on med rights. Reference herein to any upeciffe commercial products, procest, ar utricte by trade name. Trademark, manufacturer, or othernine. Joes not necinsarils

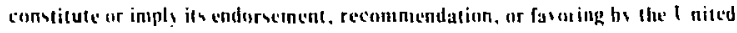

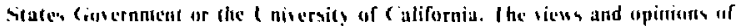
authors exprewed herein do not netewarily state or reflect thone of the I nited

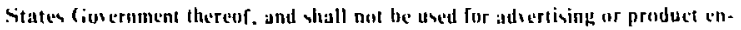
dorsement purpunen. 


\section{Figure Captions}

1. Four-electrode geometry for plasma electrode Pockels cells.

$\therefore$ Electrical circuit used to drive the $5 \times 5 \mathrm{~cm}$ aperture plasma electrode Pockels cell.

3. Electro-optic crystal-glass plate sandwich construction and polarizer orientation for high voltage Pockels cells.

4. Voltage pulse applied to the $5 \times 5 \mathrm{~cm}$ Pockels cell.

3. Optical pulse switched out by the $5 \times 5 \mathrm{~cm}$ Pockels cell.

v. Comparisun of experimental points with model calculations of optical rise-tine from 10 to $9 ! 3 \%$ transmission vs. measured peak pre-ionization current in the $b \times b$ cm aperture Pockels cell.

i. Miodel calculations of optical signal (transmission) vs. time for a $30 \times 30 \mathrm{~cm}$ aperture KDP Pockels cell at points on the near (-...) and far (_-) edges of the crystal face, from the main high voltage pulser electrodes. A pre-ionization current of 120 amps per plasma sheet is assumed.

$\therefore$ Model calculations of optical rise-time to $95 \%$ transmission for a $30 \times 30 \mathrm{~cm}$ aperture kUP Pockels call vs. the pre-ionization currer.t per plasild sheet. Calculations are performed for a $50 \Omega$ and a $255_{6}$ driver. 
Table 1. KDP Pockels Cell Design and Projected Performance

\begin{tabular}{|c|c|c|c|c|c|c|c|}
\hline Oinensions & $\mathrm{t}$ & $v_{0 \pi} / v_{k \pi}$ & $V_{0 \pi}$ & $\mathrm{R}_{\text {driver }}$ & $c_{\text {total }}$ & $1.94 R C$ & $\mathrm{t} .95^{(\operatorname{mode} l)}$ \\
\hline $5 \times b \times 1 \quad \mathrm{Cln}$ & $0.3 \mathrm{~cm}$ & 4 & $77.4 \mathrm{kV}$ & $50 \Omega$ & $11.1 \mathrm{pf}$ & $1.1 \mathrm{~ns}$ & $3.3 \mathrm{~ns}$ \\
\hline $15 \times 15 \times 2 \mathrm{~cm}$ & $1.0 \mathrm{~cm}$ & 6 & $116.0 \mathrm{kV}$ & $50 \Omega$ & $33.2 \mathrm{pf}$ & $3.2 \mathrm{~ns}$ & $8.0 \mathrm{~ns}$ \\
\hline $30 \times 30 \times 3 \mathrm{~cm}$ & $2.0 \mathrm{~cm}$ & 7.67 & $148.3 \mathrm{kV}$ & $25 \Omega$ & $69.3 \mathrm{pf}$ & $3.4 \mathrm{~ns}$ & $12.2 \mathrm{~ns}$ \\
\hline
\end{tabular}


Table 2. KD*P Pockels Cell Design and Projected Performance

\begin{tabular}{|c|c|c|c|c|c|c|c|}
\hline vimens ions & $\mathrm{t}$ & $v_{0 \pi} / V_{k \pi}$ & $V_{0 \pi}$ & $R_{\text {driver }}$ & $c_{\text {total }}$ & $1.94 \mathrm{RC}$ & $t_{\left..95^{(m o d e l}\right)}$ \\
\hline $\sin 5 \times 1 \cos$ & $0.3 \mathrm{~cm}$ & 7.75 & $57.4 \mathrm{kV}$ & $50 \Omega$ & $12.9 \mathrm{pf}$ & $1.3 \mathrm{~ns}$ & $3.8 \mathrm{~ns}$ \\
\hline $15 \times 15 \times 2 \mathrm{~cm}$ & $1.0 \mathrm{~cm}$ & 12.25 & $90.7 \mathrm{kV}$ & $50 \Omega$ & $36.6 \mathrm{pf}$ & $3.6 \mathrm{~ns}$ & $8.9 \mathrm{~ns}$ \\
\hline $30 \times 30 \times 3 \mathrm{~cm}$ & $2.0 \mathrm{Cill}$ & 16.0 & $118.4 \mathrm{kV}$ & $25 \Omega$ & $74.7 \mathrm{pf}$ & $3.6 \mathrm{~ns}$ & $13.4 \mathrm{~ns}$ \\
\hline
\end{tabular}




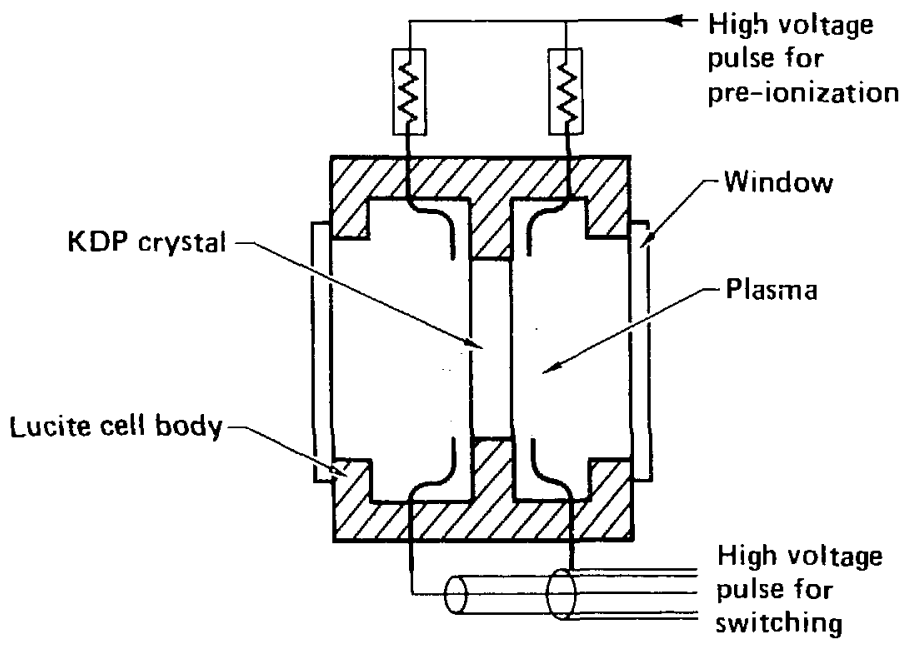

Figure 1 


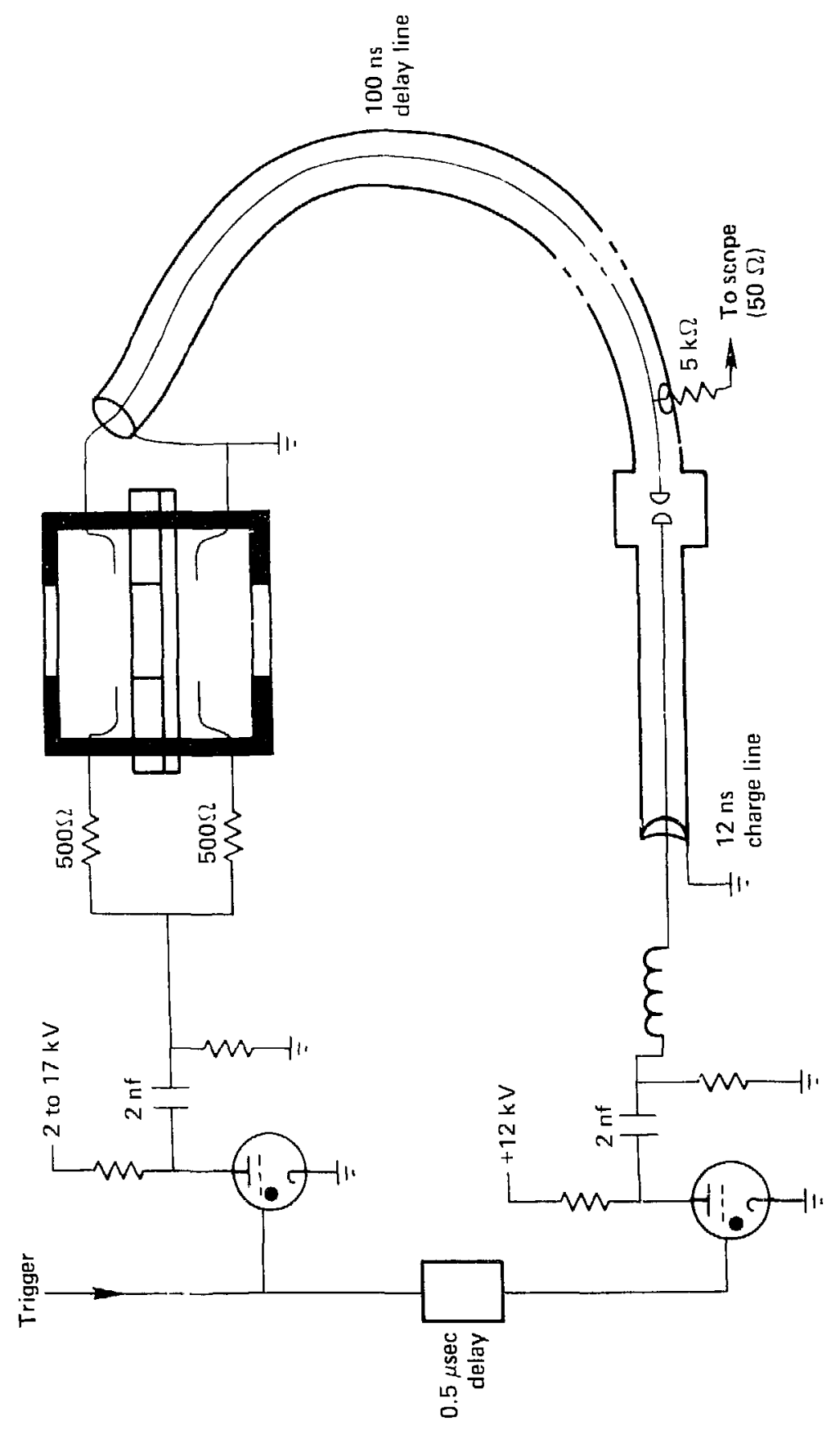

告 


$$
\text { f }
$$




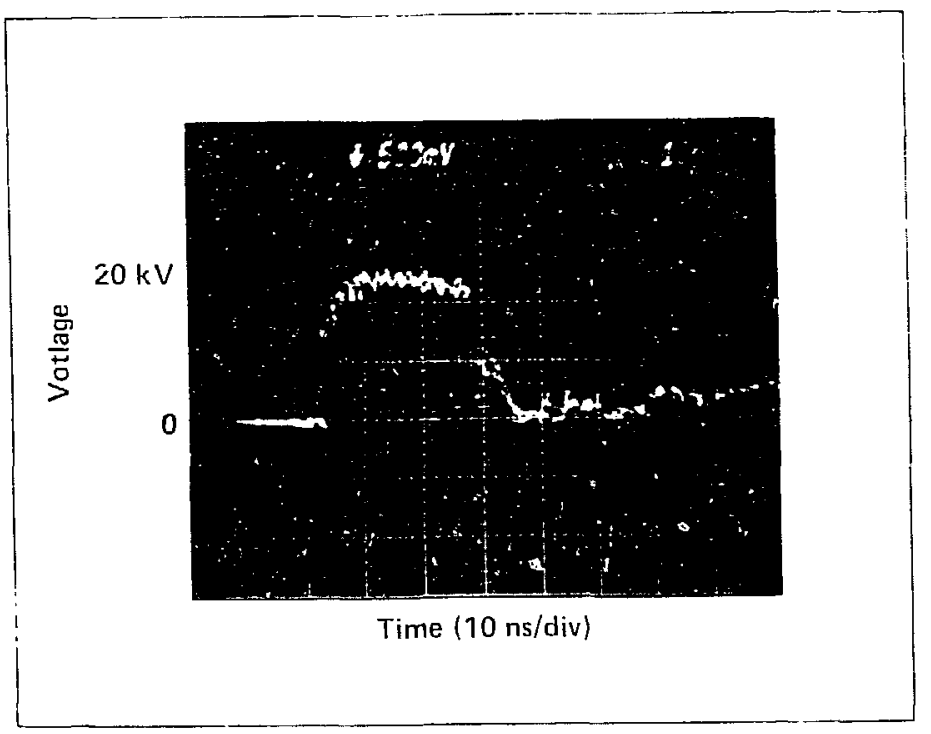

Figure 4 


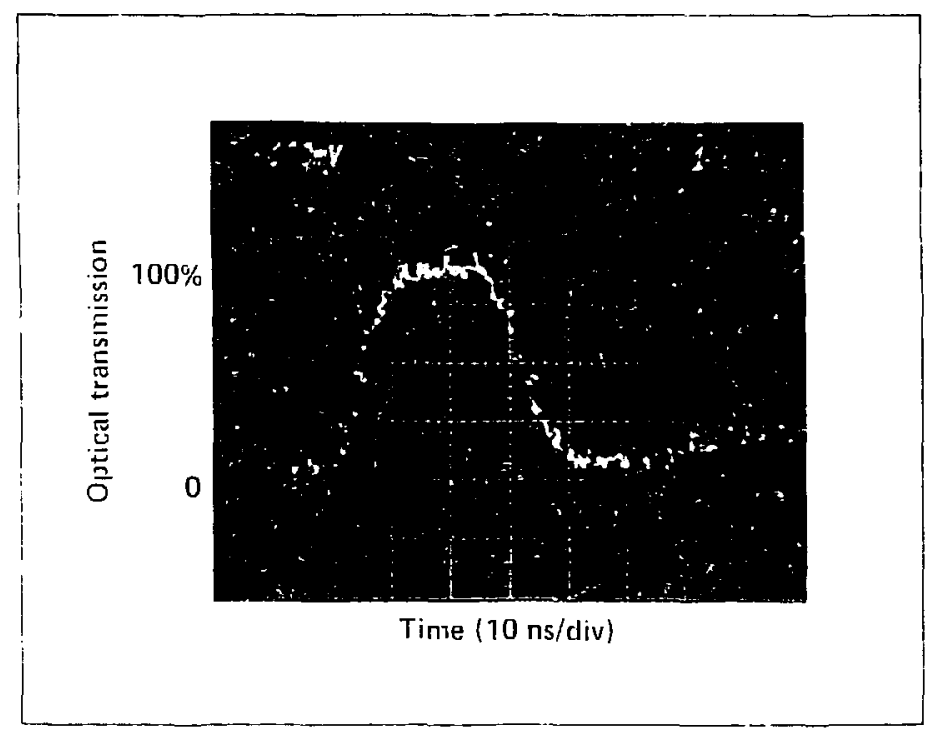

Figure 5 


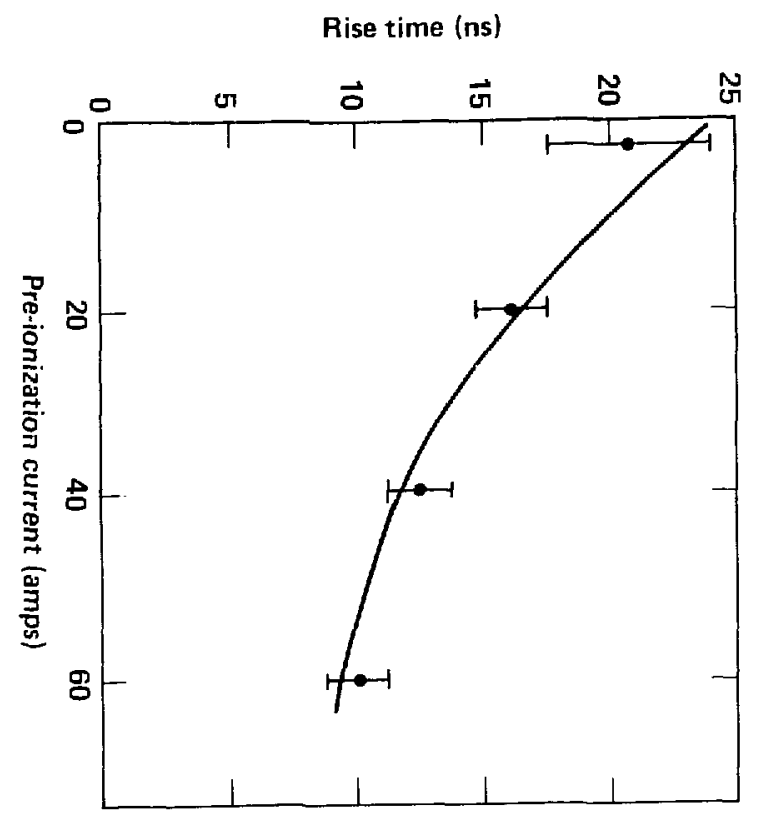




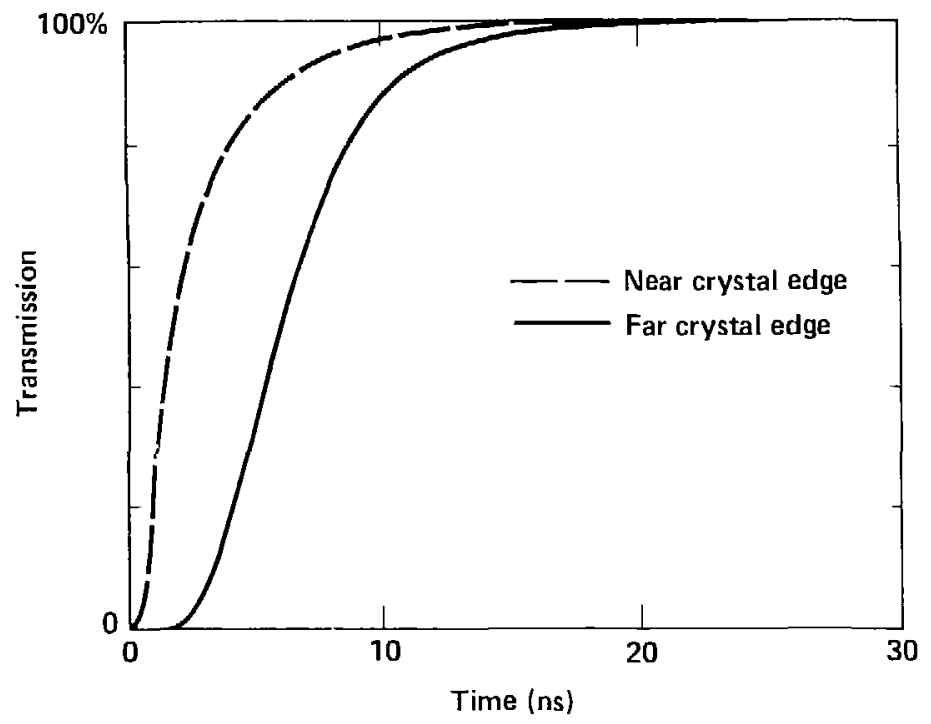

Figure 7 


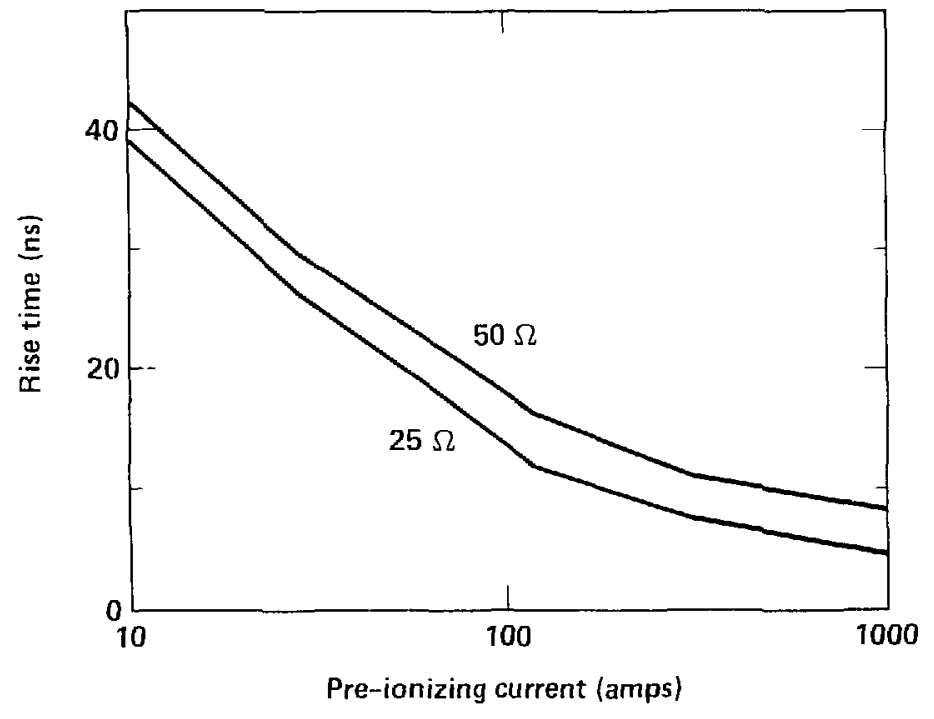

Figure 8 